\title{
Stable Isotopes for Tracing Mammalian-Cell Metabolism in vivo
}

\author{
Juan Fernández-García 1,2*, Patricia Altea-Manzano 1,2, Erica Pranzini 1,2,3, Sarah-Maria Fendt 1,2* \\ ${ }^{1}$ Laboratory of Cellular Metabolism and Metabolic Regulation, VIB-KU Leuven Center for Cancer Biology, VIB, Herestraat 49, 3000 Leuven, Belgium \\ ${ }^{2}$ Laboratory of Cellular Metabolism and Metabolic Regulation, Department of Oncology, KU Leuven and Leuven Cancer Institute (LKI), Herestraat 49, \\ 3000 Leuven, Belgium \\ ${ }^{3}$ Department of Experimental and Clinical Biomedical Sciences, University of Florence, Viale Morgagni 50, 50134 Florence, Italy \\ *Correspondence: juan.fernandezgarcia@kuleuven.vib.be (Fernández-García, J.), sarah-maria.fendt@kuleuven.vib.be (Fendt, S.-M.) \\ Laboratory website: https://www.vibcancer.be/sarah-maria-fendt \\ Twitter: @FendtLab
}

Keywords: in vivo metabolism; stable-isotope tracers; tracer analysis; metabolic models

\section{Highlights}

- Stable-isotope measurements are increasingly used to probe mammalian-cell metabolism in vivo

- The selection of stable-isotope tracer(s) and tracer administration approach is key to maximize the information extracted from in vivo measurements

- Metabolic models integrating stable-isotope tracer measurements in tissues and plasma allow obtaining quantitative readouts of in vivo metabolism at the whole-organ/whole-body levels

- Tissue heterogeneity and metabolic compartmentalization need to be considered during data interpretation

- The development of single-cell/single-organelle metabolomic approaches will advance our understanding of in vivo metabolism

\begin{abstract}
Metabolism is at the cornerstone of all cellular functions, and mounting evidence of its deregulation in different diseases emphasizes the importance of a comprehensive understanding of metabolic regulation at the wholeorganism level. Stable-isotope measurements are a powerful tool for probing cellular metabolism, and as a result are increasingly used to study metabolism in in vivo settings. The additional complexity of in vivo metabolic measurements requires paying special attention to experimental design and data interpretation. Here, we review recent work where in vivo stable-isotope measurements have been used to address relevant biological questions within an in vivo context, summarize different experimental and data interpretation approaches and their limitations, and discuss future opportunities in the field.
\end{abstract}

\section{Metabolism-A Central Node for Cellular Processes}

Metabolism can be seen as the engine of the cell, providing energy, redox co-factors and building blocks for cell maintenance, growth and renewal, as well as playing a key role in modulating cell signaling [1,2]. To orchestrate all these functions, metabolism consists of a complex network of genes, enzymes, and metabolites, steadily modulated in response to different stimuli [3-5]. Defining the mechanisms at the basis of this regulation and understanding their physiological role is among the most important pursuits in biological and medical research [6], particularly since the realization that many pathologies are driven by metabolic deregulations [7]. An in-depth understanding of metabolic pathways in vivo and how these are deregulated in different diseases is thus fundamental for the discovery of new therapeutic targets and clinical biomarkers, enabling the development of more robust diagnosis approaches and personalized treatments eventually improving the overall outcome for patients [8]. In this context, stable-isotope tracers (see Glossary) have become a standard for probing cellular metabolism [9], and their increasing implementation in in vivo settings has revolutionized our current understanding of mammalian metabolism in health and disease, unraveling novel regulatory principles at both the cellular and whole-organism level $[10,11]$. In this review, we summarize the latest advances in in vivo metabolic measurements using stable- 
isotope tracers, highlighting the importance of systems-level integrative approaches and careful experimental design, pointing out open challenges and opportunities for advancing the field, and outlining strategies and potential pitfalls when interpreting these measurements (Figure 1).

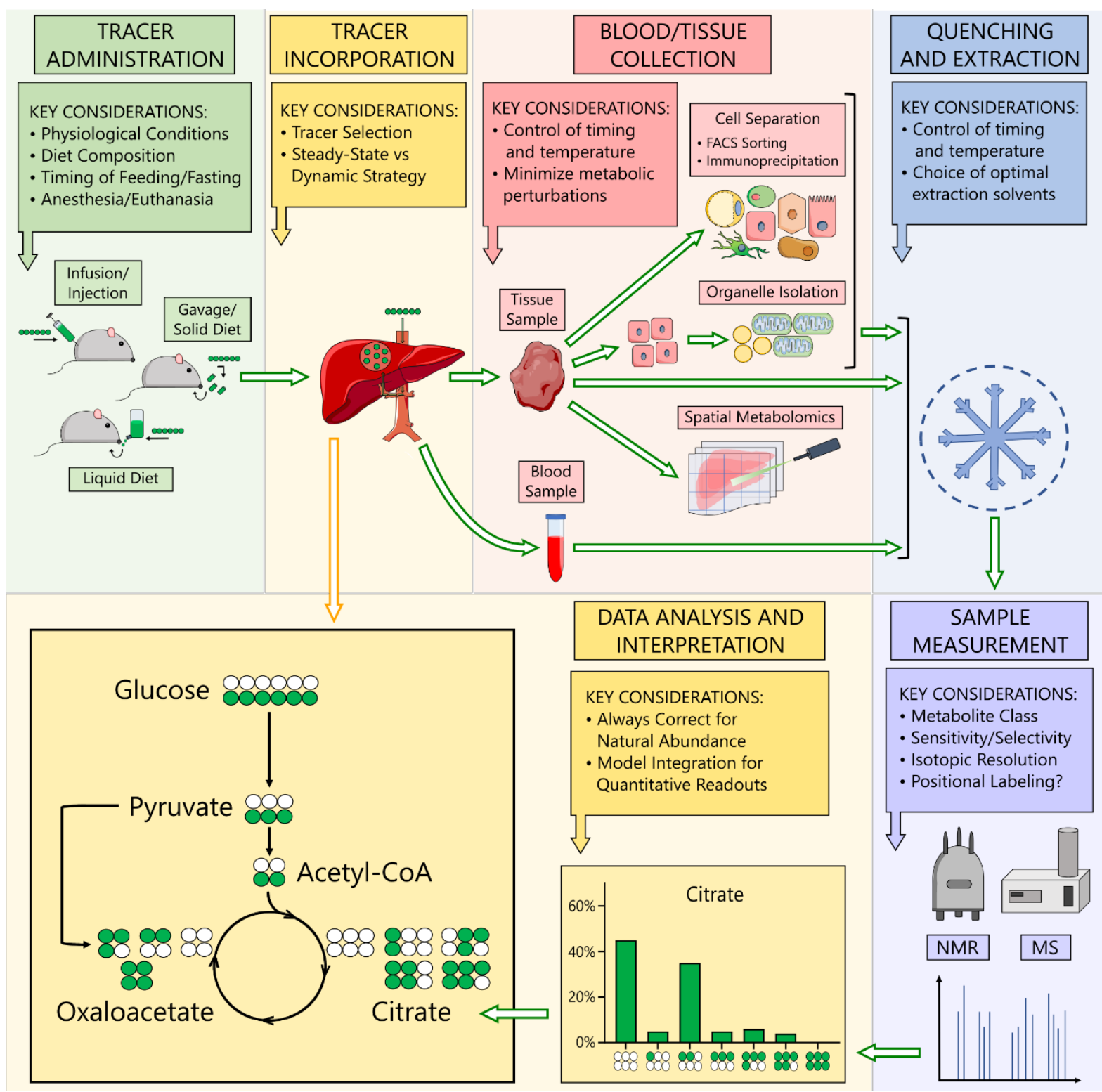

Figure 1. Outline of the different steps involved in an in vivo stable-isotope tracing experiment. Appropriate stable-isotope tracers chosen based on the biological question of interest are administered to the model organism using various approaches such as infusions/injections, gavage or solid/liquid diets. Tissue or blood samples are later collected from the subject and processed according to the readout of interest. For tissue samples, this may include (a) whole-tissue quenching, (b) quenching following cell and/or organelle isolation, or (c) preparation for spatial metabolomics analysis. Metabolites are then extracted to measure the incorporation of isotopic label from the tracer into downstream metabolic products, using analytical techniques such as mass spectrometry (MS) or nuclear magnetic resonance (NMR). The isotopic enrichment profiles of different metabolites can then be assessed and interpreted to gain insight on the activities of different intracellular metabolic pathways. Alternatively, these enrichment profiles can be combined with extracellular (blood) measurements and integrated into systems-level metabolic models, to achieve quantitative readouts of the subject's metabolic state. 


\section{Tracer-Based Methods for Measuring Cellular Metabolism in vivo}

Many complementary methods exist to study metabolism in vivo and, consequently, the selection of a specific approach (or set of approaches) depends largely on the biological question being addressed. Non-tracer based methods, such as assessing bioenergetics by measuring dynamic changes in oxygen consumption [12] or evaluating changes in metabolite levels via metabolomics [13], provide relatively straightforward ways of probing the metabolic state of an organism in vivo. However, when a deeper understanding of the activity of specific metabolic pathways is sought, the readouts provided by these methods alone may not be sufficient [14]. In such cases, tracerbased methods can be used to enable interrogation of intracellular metabolism from a pathway-centric perspective [15]. In tracer-based approaches, isotopically enriched nutrients (or tracers) are administered to a biological system, and the resulting metabolic conversions are tracked based on the incorporation of the isotopic label into downstream products. This enables a direct interrogation of the activities of different metabolic pathways, and an assessment of the contributions of different enzymatic reactions to the production or consumption of specific metabolites [16]. For instance, with tracer-based approaches one can tell whether observed changes in metabolite levels between two biological conditions are due to increased fluxes from synthesizing enzymes, decreased fluxes towards consuming enzymes, or alterations in metabolite transport across intra/extracellular membranes, which would not be attainable using only metabolomics [14].

Both radioactive (e.g. ${ }^{18} \mathrm{~F},{ }^{3} \mathrm{H},{ }^{14} \mathrm{C}$ ) and stable (e.g. ${ }^{2} \mathrm{H},{ }^{13} \mathrm{C},{ }^{15} \mathrm{~N}$ ) isotope tracers are used to study in vivo metabolism. Traditionally, radioactive tracers have been chosen for their high sensitivity [16] and specificity, making them useful for interrogating the activity of single, predefined pathways. For instance, the radioactive glucose analog ${ }^{18} \mathrm{~F}-\mathrm{FDG}$, which provides a direct readout of glycolytic activity (a characteristic of many tumors), is widely used for diagnosis and treatment-response assessment in cancer patients $[17,18]$. In contrast, stable-isotope tracers, although at the expense of sensitivity, will generally lead to increased labeling depth, allowing to interrogate multiple pathways at once, thus maximizing the wealth of information gathered from a single experiment $[19,20]$. In addition, prolonged and repeated administration is more feasible than with their radioactive counterparts, which makes them particularly attractive for in vivo studies, where the number of experimental subjects is necessarily limited. For all of this, stable-isotope tracers have become increasingly popular in in vivo metabolic studies over the recent years (Table 1). In this review, we describe important aspects to consider in the use of stable-isotope tracers in order to accurately interrogate metabolic pathways in in vivo systems.

\section{Approaches for in vivo Tracer Administration and Measurement}

Multiple approaches for stable-isotope tracer delivery in vivo have been successfully implemented to date, including oral administration via the diet or by gavage, or direct introduction into the circulation via intravenous infusions or intraperitoneal injections (Table 1) [21-23]. In general, no administration method can be considered superior to others in all respects, and thus the choice of a specific approach should be driven by the biological question of interest and the desired readout. In any case, and regardless of the chosen approach, attention must always be paid to the control and standardization of the experimental conditions during tracer administration and further sampling to enable extracting reproducible and biologically sound conclusions from tracer experiments (Text Box 1).

Infusions are perhaps the most extended method for tracer administration in recent in vivo measurements (Table 1). In infusion approaches, tracers are administered at a constant rate into the bloodstream for a defined period of time, after which label incorporation into downstream tissue metabolites is assessed. An advantage of continuous infusions relative to discrete tracer-administration approaches (e.g. bolus or injections) is that sharp transient effects associated with nutrient administration peaks are minimized [24]. In addition, since tracer administration can continue long enough for plasma-metabolite pools to turn over multiple times, a constant tracer enrichment in the bloodstream can be more easily achieved. This can simplify the interpretation of label-incorporation patterns (Text Box 2) into tissue metabolites, since tracer turnover does not have to be accounted for (Text Box 3). Furthermore, the increased label persistence in the bloodstream will also lead to increased labeling depth. This enables interrogation of more complex metabolic pathways [25], and also facilitates achieving a constant (or nearly constant) isotopic enrichment in downstream tissue metabolites (i.e. an isotopic steady-state), which further simplifies interpretation (Text Box 4). Infusions have, nevertheless, the drawback of an increased invasiveness and technical complexity [26], as well as cost (due to the generally larger amounts of tracer required), and may further not be optimal when investigating the fate of dietary metabolites. Indeed, some studies have shown significant differences in tissue-specific metabolization of commonly ingested nutrients (e.g. fructose) when infused in the circulation or administered orally [27]. In such cases, more biologically representative results may be obtained by oral tracer administration via diet-based feeding or continuous gavage, with the latter sharing the advantages, but also the drawbacks (particularly in terms of invasiveness) of infusions. In this sense, non-invasive methods for prolonged oral tracer delivery via liquid or traditional (solid) diet emerge as an interesting compromise, allowing 
long-term tracer exposure while minimizing stress and technical complexity and, in the case of liquid diets [22,28], also reducing costs (as these can be easily prepared in house).

\section{The Importance of Selecting the Right Tracer(s)}

A key to success in in vivo stable-isotope measurements lies in the selection of the tracer(s) that will be administered to the research subject. Both the identity (e.g. glucose, glutamine...) and the number, elemental nature (e.g. ${ }^{13} \mathrm{C}$, $\left.{ }^{15} \mathrm{~N} . ..\right)$, and position of the isotopically-labeled atoms in a tracer will determine which downstream metabolites and pathways will potentially incorporate label from it [29-31]. Tracer selection must therefore be driven by the identification of those metabolic pathways whose interrogation will allow to better address the biological question at hand. We exemplify this here by reviewing recent work on in vivo stable-isotope measurements where novel insight on metabolism was attained thanks to appropriate tracer selection (Table 1). For a comprehensive compilation of optimal tracers to probe specific pathways, the reader is further referred to Table 2 of [9].

Uniformly-labeled tracers (i.e. molecules with all atoms of a given element replaced by stable isotopes) are widely used for probing metabolism because of their potential to act as global tracers, transferring label into multiple downstream pathways at once. Among them, ${ }^{13} \mathrm{C}_{6}$-glucose remains the most popular in vivo tracer, due to its ability to swiftly label many pathways within central carbon metabolism (e.g. glycolysis, the TCA cycle, their branching pathways...) and its relatively low cost. ${ }^{13} \mathrm{C}_{6}$-glucose has, for instance, been widely used to shed new light on the role of glucose metabolism in cancer [24,26,32,33]. Among other things, such studies have shown how, contrary to the notion that increased glucose uptake is mostly meant to support tumor engagement in aerobic glycolysis (the so-called Warburg effect), elevated glucose oxidation and glucose-derived-pyruvate anaplerosis are also displayed by many cancers in vivo. Aside from ${ }^{13} \mathrm{C}_{6}$-glucose, uniformly-labeled tracers based on other molecules and isotopes (e.g. ${ }^{15} \mathrm{~N},{ }^{2} \mathrm{H}$...) are increasingly used in in vivo measurements to globally interrogate pathways involved in fatty acid [28,34], ketone body [34,35], or amino acid [36,37] metabolism, among others. The study in [36] is an interesting example due to the use of an unconventional tracer, consisting in ${ }^{15} \mathrm{~N}$-labeled mouse serum albumin. By replacing circulating albumin by this ${ }^{15} \mathrm{~N}$-labeled analog in tumor-bearing mice and assessing ${ }^{15} \mathrm{~N}$ enrichment in tissue amino acids, the authors could demonstrate how some tumors are able to catabolize extracellular proteins to fuel their metabolism. This exemplifies, once more, the importance of guiding tracer selection based on the biological question one intends to answer.

Despite the predominant use of uniformly-labeled tracers, positionally-labeled tracers (i.e. molecules with only some specific atoms replaced by stable isotopes) are also widely adopted in in vivo measurements, due to their superiority for interrogating specific pathways. The rationale is that, in reactions where the substrate molecule is broken, a positionally-labelled metabolite will transfer label only to specific reaction products. This in turn allows assessing the relative activity of different pathways forking from the same metabolite, by comparing the levels of labeled and unlabeled products further downstream those pathways. Positionally-labelled ${ }^{13} \mathrm{C}$-glucose tracers have, for instance, been used to evaluate the activity of the different branches of the pentose-phosphate pathway in neuronal tissue [38]. Another example is the recent use of ${ }^{13} \mathrm{C}_{3}$-fructose tracers, alternatively labeled on either the first or last 3 carbons, to show how fructose catabolism to organic acids in the small intestine of mice proceeds largely via glycerate [27] (Text Box 3). An extra benefit of positionally-labeled tracers is that their incorporation will generally result in labeling patterns distinct from those originating from uniformly-labeled tracers. This can, in turn, be exploited to assess the relative contributions of different nutrients to a given pathway, by administering appropriately chosen combinations of positionally-labeled and uniformly-labeled tracers for either nutrient. For instance, simultaneous $\left[1,6-{ }^{13} \mathrm{C}_{2}\right]$-glucose and $\left[1,2-{ }^{13} \mathrm{C}_{2}\right]$-acetate infusions (which, when oxidized to Acetyl-CoA, yield distinct labeling patterns in TCA-cycle intermediates) have been used to demonstrate a shift from glucose to acetate oxidation in brain tumors [39], a highly-relevant observation in light of recent evidence that the brain produces substantial amounts of acetate [40]. Similarly, short co-infusions of ${ }^{13} C_{6}$-glucose and $\left[3-{ }^{13} C_{1}\right]$-lactate (leading again to distinct TCA-cycle labeling patterns, Text Box 4) were recently used to show how some lung tumors can rely on circulating lactate to fuel their TCA cycle [20].

Aside from demonstrating the utility of positionally-labeled tracers, the last examples evidence the power of performing measurements with multiple tracers to unravel the complexities of in vivo metabolism [41]. Importantly, multiple-tracer approaches are not limited to tracer co-administration, but may also be implemented as parallel single-tracer measurements, in cases where co-administration would lead to overlapping labeling patterns in the products of interest. For instance, parallel infusions of ${ }^{13} \mathrm{C}_{6}$-glucose and ${ }^{13} \mathrm{C}_{5}$-glutamine have been used to show how, contrary to in vitro observations, lung tumors rely mainly on glucose-derived-pyruvate (rather than glutamine) to fuel their TCA cycle in vivo [19], evidencing the importance of cell-extrinsic factors in modulating in vivo metabolism. A caveat of in vivo parallel tracing experiments is that they can become highly resource-intensive (e.g. in mouse experiments requiring tissue collection, where one animal is needed for each replicate under each tracer 
of interest), or even intractable (e.g. in human experiments requiring biopsy collection). It is expected, nevertheless, that the progressive implementation of high-resolution mass spectrometry (HR-MS) analytical methods, capable of resolving label incorporation from different stable isotopes (e.g. ${ }^{13} \mathrm{C},{ }^{15} \mathrm{~N}$, or ${ }^{2} \mathrm{H}$ ) [42-44], will soon enable researchers to routinely perform measurements based on co-administration of multiple tracers containing such different isotopes, enhancing the wealth of information extracted from a single in vivo experiment.

\section{Integrating Measurements and Models to Quantify Metabolism at the (Inter-)Organ Level}

Most studies above used stable-isotope tracers to determine the relative importance of different metabolic pathways in a given in vivo setting, or to assess qualitative changes in pathway activities between different biological conditions, an approach known as tracer analysis [14]. While tracer analysis can be highly informative, sometimes one may want to determine quantitative information about the metabolic conversion rates or fluxes in a system $[45,46]$. Various approaches for inferring metabolic fluxes based on stable-isotope measurements have been developed over the last decades, with metabolic flux analysis (MFA) being the most widely-adopted [47]. In standard isotopically-stationary MFA, measured steady-state labeling patterns of intracellular metabolites are combined with measurements of extracellular nutrient uptake/secretion and cell growth, and integrated into a mathematical model of atom-transfer due to intra/extracellular metabolic fluxes. A computational iterative process is then performed to estimate the flux values that best fit the measured labeling patterns, under the constraints imposed by uptake/secretion and biomass production rates for growth. Alternatively, when reaching isotopic steady-state is not feasible, time-dependent labeling patterns can be integrated into a dynamic label-incorporation model to estimate fluxes via isotopically-non-stationary MFA (INST-MFA), although at the expense of increased computational load (and with the extra requirement for intracellular metabolite pool-size measurements). While routinely implemented in vitro, applying MFA in vivo presents some handicaps. One major issue is the determination of in vivo uptake/secretion rates which, as discussed below, is complicated by the exchange of metabolites between different organs via the circulation. In addition, given the often-short duration of in vivo tracer experiments, steadystate labeling will not always be reached within tissues, as required by isotopically-stationary MFA, while dynamic in vivo measurements will typically be feasible only for blood samples, limiting the applicability of INST-MFA. Furthermore, in vivo tissues are generally far from homogeneous at the cellular level, as assumed by MFA. Accordingly, only a few pioneering studies have dealt with formal MFA-based flux determination at the wholeorgan level, and these have relied either on extensive parallel-tracer measurements in ex vivo-perfused organs [48], or on carefully designed positional-enrichment determination strategies for highly-specialized tissues like the liver $[49,50]$.

As noted earlier, a layer of complexity in in vivo metabolic measurements originates from the exchange of metabolic products between different organs. Indeed, in order to maintain whole-body homeostasis, different tissues will have very different metabolic programs, and thus will exchange different metabolites with the circulation [40]. As a result, even the administration of a single tracer will inevitably lead to the appearance of multiple labeled metabolites in the bloodstream, all of which may potentially contribute isotopic labeling to any given tissue of interest. Monitoring the identity and enrichment of different labeled nutrients in the circulation is hence key in in vivo measurements, as this will impact not only quantitative, but also qualitative data interpretation (Text Boxes 3-4). A further implication of this inter-organ metabolite exchange, is that, as introduced above, it complicates the quantification of nutrient uptake/secretion rates by specific tissues. Indeed, whereas in in vitro or ex vivo cultures these can simply be inferred from measurements of "initial" vs "spent" media [41], their determination in vivo is non-trivial. Nevertheless, a variety of approaches, combining systems-level stable-isotope measurements and metabolic models, have been successfully implemented over recent years to quantitatively tackle this inter-organ exchange problem. An example, based on integrating steady-state plasma-enrichment readouts from several individual-tracer infusions in mice into a systemic circulatory-turnover model, is given in [51], enabling the quantification of wholebody circulatory turnover fluxes for a variety of metabolites (Text Box 3). By further combining these measurements with tissue-enrichment readouts and a whole-body flux model for glucose/lactate incorporation, the authors showed how circulating lactate is not only an energy source in tumors [20], but interestingly also in healthy tissues. An alternative, organ-specific approach was in turn implemented in [27], based on integrating time-resolved measurements of ${ }^{13} \mathrm{C}$-labeled glucose and fructose levels in arterial and portal-vein blood into a model for intestinal nutrient conversion, to quantify the fate of fructose catabolism in the small intestine of mice, demonstrating how ingested fructose is an important source of both glucose and organic acids. Taking this one step further, a novel systems-level approach was recently implemented in [40], based on quantifying differences in metabolite levels between arterial blood and multiple individual veins draining specific organs in pigs (in an in vivo analogy of the in vitro "initial" vs "spent" media approach), which allowed the authors to infer absolute organ-specific metabolite consumption/secretion profiles and inter-organ metabolite exchange patterns. All in all, these examples highlight the importance of complementing tissue labeling data with extracellular (i.e. blood) measurements and systems- 
level models to attain a deeper understanding of in vivo metabolism, and demonstrate how relevant quantitative readouts of in vivo metabolism may be obtained without necessarily resorting to complex mathematical or computational models.

\section{Current Challenges and Opportunities: Towards Single-Cell/Organelle Tracer Measurements to Unravel Metabolic Heterogeneity}

Altogether, the examples covered in the previous sections evidence the importance of studying metabolism in an in vivo setting to enable recapitulating the physiology of living organisms. They further demonstrate the advances attained over recent years in the study of in vivo metabolism, driven by the implementation of stable-isotope tracer measurements and their combination with metabolic models. Nevertheless, the road to a complete understanding of in vivo metabolism is still long, with some hurdles that will need to be tackled in the coming future.

A major challenge when studying metabolism in vivo stems from the fact that tissues are generally nonhomogeneous at the cellular level, instead comprising different cell types with diverse metabolic programs [52]. Moreover, cell-cell interactions, as well as varying levels of nutrient perfusion within a tissue, will inevitably result in altered metabolic traits, even for cells of identical origin [10,24]. Intra-tissue heterogeneity is a confounding factor in metabolic measurements, since these generally rely on metabolite extraction from bulk-processed tissues. Hence, measured metabolite levels and labeling patterns will represent a population-average of all cells contained within a tissue. Whereas spatial heterogeneities have been dealt with by sampling from different regions of a tissue (e.g. differently perfused areas within a tumor [24]) and linking them to specific metabolic states, resolving mixed-cell populations is still challenging. An approach to tackle this issue has been proposed consisting in using FACS to presort heterogeneous cell populations based on cell-type-specific markers prior to metabolic quenching and metabolite extraction [53]. This approach was benchmarked on in vitro ${ }^{13} \mathrm{C} /{ }^{15} \mathrm{~N}$-labeled homogeneous cultures, showing how the resulting mass distribution vectors (MDVs) were virtually unaltered by FACS, thus being representative of the actual intracellular metabolism before sorting [54]. However, as also indicated therein and later confirmed by further studies [55,56], significant changes in the levels of many metabolites were also observed in those cells upon sorting, particularly regarding redox balance, likely due to the mechanical stress experienced by the cells during FACS [55]. With this in mind, a window of opportunity in this area could be opened by the implementation of cell separation techniques minimizing the stress experienced by the isolated cells. In this sense, methods based on magnetic immunoprecipitation could, as suggested below, be an interesting alternative to consider.

Aside from intra-tissue heterogeneity, another long-standing challenge when studying mammalian-cell metabolism ensues from the compartmentalized nature of eukaryote metabolism [57,58]. As with intra-tissue heterogeneity, the diversity in organelle metabolism will generally not be resolvable with isotope tracing, since organelle-specific labeling patterns will be masked upon whole-cell pooling for extraction. Exceptionally, specific aspects of compartmentalized metabolism have been probed in in vitro tracing experiments, based on judicious tracer selection and the identification of appropriate reporter metabolites whose intracellular labeling patterns univocally reflect the differential activity of mitochondrial and cytosolic enzymes [32,59,60]. These approaches relied, nevertheless, on assumptions about the extracellular medium composition [32], the activity of certain reactions [60], or the expression of mutant reporter enzymes [32,59], limiting their applicability in vivo. Resolving compartmentalized metabolism in vivo thus seems to call for technical approaches allowing to physically fractionate cells into their different organelles. Several methods for rapid isolation of mitochondrial [13,61] and lysosomal [62] fractions from whole cells have been implemented in vitro to probe the metabolism of these organelles. Interestingly, one of these approaches, based on epitope-tagging of mitochondria for further separation via magnetic immunoprecipitation [13], was recently extended to enable its application for specific cell types in vivo [63]. This was attained by genetically engineering mice to conditionally express a mitochondrial epitope-tag subject to the co-expression of Cre recombinase, with the latter driven in turn by cell-type specific promoters. Such promising technique, allowing to simultaneously resolve tissue and organelle heterogeneity in in vivo measurements, has the only caveat that it requires the introduction of genetic constructs in the organism of interest, thus limiting its in vivo application to mouse experiments.

Building up on these advances, the next big leap for stepping forward our understanding of in vivo metabolism in heterogeneous mammalian tissues will consist in the establishment of single-cell and single-organelle metabolomics approaches. In a time when single-cell techniques are blooming in genomics, epigenomics, transcriptomics, and proteomics [64,65], single-cell metabolomics is still in its infancy [66]. Nevertheless, recent studies have demonstrated the feasibility of different techniques for profiling the metabolome at the single-cell level from both cell cultures $[67,68]$ and freshly resected tissues [69]. Among these techniques, MS-imaging (MSI) spatial metabolomics [70] is perhaps the most widely applicable, having proven the ability to characterize both 
metabolite levels and isotopic-labeling patterns at sub-cellular (and even sub-organelle) resolutions [71]. The current caveat of MSI-based approaches is a necessary tradeoff between spatial resolution, metabolite coverage, and sensitivity. However, it is expected that the continuous improvements in MSI instrumentation [72-74], together with the development of more efficient ionization methods and alternative sampling approaches $[66,75]$, will soon enable single-cell (and, eventually, single-organelle) tracer analysis and metabolomics to become routinely applied in the study of in vivo metabolism.

\section{Concluding Remarks:}

Studying metabolism in vivo is fundamental for deciphering the molecular mechanisms driving a variety of biological process and diseases. In this context, the development of stable-isotope tracing approaches has revolutionized our ability to interrogate metabolic pathway activities in in vivo settings. To maximize the information extracted from tracer experiments, several key aspects should be considered. First, tracer selection must be driven by the identification of those metabolic pathways allowing to better address the biological question of interest. In this sense, uniformly-labeled tracers are useful global tracers, whereas positionally-labeled tracers should be adopted for interrogating specific pathways. Furthermore, combining measurements with multiple tracers allows expanding the number of pathways interrogated in a given system. Second, the experimental conditions must always be tightly controlled and standardized to ensure reproducible and biologically representative measurements. Third, the selection of a specific platform to quantify the tracer incorporation into downstream metabolites must be determined by the nature of the samples and the goal of the study. Lastly, complementing tissue labeling data with extracellular measurements and systems-level models opens up a wide range of possibilities to attain quantitative readouts of in vivo metabolism at an inter-organ level.

Despite the significant advances recapitulated in this review, further efforts in the combination of stable-isotope based approaches with metabolic models are required to enable obtaining more comprehensive quantitative readouts of in vivo metabolism. In addition, the compartmentalized nature of eukaryote metabolism, as well as the intra-tissue and intra-cellular heterogeneity of mammalian tissues, remain major challenges to overcome for further improving our understanding of mammalian-cell metabolism (see Outstanding Questions). Ongoing developments in single-cell metabolomics techniques, together with the continuous improvements in instrumentation, will soon open up a new window for single-cell tracer analysis and metabolomics to become the next gold standard in the study of in vivo metabolism.

\section{Outstanding Questions:}

- The application of stable-isotope labeling approaches is still limited by the high costs of isotopically labeled substrates. What strategies can be implemented to reduce tracer production costs?

- How far are we from seeing single-cell/single-organelle tracer-metabolomics approaches becoming routinely established? And what alternative methods could be implemented to deal with intra-tissue heterogeneity and metabolic compartmentalization in vivo?

- A caveat of in vivo tracing experiments is that isotopic steady-state will not always be reached within tissues. Which alternative, less invasive tracer delivery methods may be implemented to allow increasing labeling time and better approach isotopic steady-state conditions in tissues?

- Difficulties for determining uptake/secretion rates in vivo limit the implementation of formal flux analysis approaches in these settings. How can existing methods allowing the determination of organ-specific metabolite consumption/secretion profiles in vivo be implemented to circumvent this limitation?

- How can stable-isotope measurements be implemented routinely in clinical settings?

\section{Acknowledgements:}

JFG is supported by an FWO postdoctoral fellowship. PAM is supported by a Marie Skłodowska-Curie Actions individual fellowship. EP is a PhD fellow supported by Region of Tuscany-FSE (Pegaso project). SMF acknowledges funding from the European Research Council under the ERC Consolidator Grant Agreement n. 771486MetaRegulation, FWO Projects and Grants, and KU Leuven Methusalem Co-funding. 
Table 1 Overview of recent in vivo stable-isotope tracer studies, including subjects of the studies, model organisms, main tracers used, tracer administration and measurement approaches, and main readouts

\begin{tabular}{|c|c|c|c|c|c|}
\hline $\begin{array}{l}\text { Subject of } \\
\text { Study }\end{array}$ & Organism & Tracers/Administration Method & Measurement & Readout & Ref \\
\hline \multicolumn{6}{|c|}{${ }^{13} \mathrm{C}_{6}$-glucose } \\
\hline $\begin{array}{l}\text { Non-small cell } \\
\text { lung cancer }\end{array}$ & Human & $\begin{array}{l}\text { Intraoperative infusion of }{ }^{13} \mathbf{C}_{6} \text {-glucose } \\
\text { in cancer patients }\end{array}$ & $\begin{array}{l}\text { GCMS } \\
\text { NMR }\end{array}$ & $\begin{array}{l}\text { Labeling patterns in tumors } \\
\text { versus adjacent matched tissues }\end{array}$ & {$[24,76]$} \\
\hline $\begin{array}{l}\text { Non-small cell } \\
\text { lung cancer }\end{array}$ & Human & 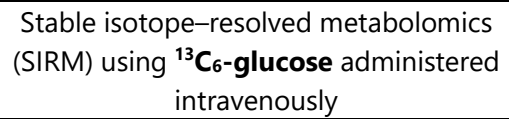 & $\begin{array}{l}\text { GCMS } \\
\text { NMR } \\
\text { HR-MS }\end{array}$ & $\begin{array}{l}{ }^{13} \mathrm{C} \text { enrichment of different } \\
\text { metabolites and determination of } \\
\text { pathway activities }\end{array}$ & [26] \\
\hline Glioblastoma & $\begin{array}{l}\text { Human } \\
\text { Mouse }\end{array}$ & $\begin{array}{c}{ }^{13} \mathbf{C}_{6} \text {-glucose infusions in patients } \\
\text { before surgical tumor resection and } \\
{ }^{13} \mathbf{C}_{5} \text {-glutamine bolus injections in tail } \\
\text { vein of mice }\end{array}$ & LCMS & $\begin{array}{l}\text { Identification of nutrient } \\
\text { microenvironment contribution } \\
\text { to support glioblastoma growth }\end{array}$ & [77] \\
\hline $\begin{array}{c}\text { Colon } \\
\text { adenocarcinoma } \\
\text { and obesity }\end{array}$ & Mouse & $\begin{array}{c}{ }^{13} \mathbf{C}_{6} \text {-glucose and }\left[1-{ }^{13} C_{1}\right] \text {-acetate } \\
\text { infusions (prime + continuous), with } \\
\text { blood sample collection from tail }\end{array}$ & $\begin{array}{l}\text { GCMS } \\
\text { LCMS }\end{array}$ & $\begin{array}{l}\text { Systemic glucose turnover and } \\
\text { oxidation by the tumor }\end{array}$ & [33] \\
\hline $\begin{array}{l}\text { Primary mouse } \\
\text { soft tissue } \\
\text { sarcomas }\end{array}$ & Mouse & $\begin{array}{l}{ }^{13} \mathbf{C}_{6} \text {-glucose infusions via surgical } \\
\text { catheterization of the jugular vein } \\
\text { exteriorized via vascular access port }\end{array}$ & LCMS & $\begin{array}{l}\text { Conversion of glucose-derived } \\
\text { pyruvate to acetate to maintain } \\
\text { acetyl-CoA pools under impaired } \\
\text { mitochondrial metabolism }\end{array}$ & [78] \\
\hline $\begin{array}{l}\text { Breast cancer } \\
\text { and lung } \\
\text { metastases }\end{array}$ & Mouse & $\begin{array}{l}{ }^{13} \mathbf{C}_{6} \text {-glucose infusions via surgical } \\
\text { catheterization of the jugular vein }\end{array}$ & GCMS & $\begin{array}{l}\text { Comparison of }{ }^{13} \mathrm{C} \text { labeling } \\
\text { patterns of different metabolites } \\
\text { in breast-cancer metastases } \\
\text { relative to primary breast tumors }\end{array}$ & {$[32,79]$} \\
\hline \multicolumn{6}{|c|}{ Alternative Tracers } \\
\hline $\begin{array}{l}\text { Fatty-liver } \\
\text { disease }\end{array}$ & Human & $\begin{array}{l}{\left[1-{ }^{13} C_{1}\right] \text {-acetate infusions in healthy }} \\
\text { subjects and measurement of }{ }^{13} \mathrm{C} \\
\text { incorporation to palmitate in very-low- } \\
\text { density lipoprotein }(V L D L) \text { in blood }\end{array}$ & LCMS & $\begin{array}{l}\text { Fraction of VLDL palmitate } \\
\text { synthesized through de novo } \\
\text { lipogenesis (DNL) and DNL } \\
\text { contribution to VLDL fatty acids }\end{array}$ & [80] \\
\hline $\begin{array}{l}\text { Pancreatic ductal } \\
\text { adenocarcinoma }\end{array}$ & Mouse & $\begin{array}{l}\text { Replacement of circulating mouse } \\
\text { serum albumin by yeast-produced } \\
\text { recombinant }{ }^{15} \mathrm{~N} \text {-labeled analog }\end{array}$ & GCMS & $\begin{array}{l}\text { Assessment of }{ }^{15} \mathrm{~N} \text { enrichment in } \\
\text { in plasma and pancreas amino } \\
\text { acids to show protein catabolism } \\
\text { can fuel tumor metabolism }\end{array}$ & {$[36]$} \\
\hline $\begin{array}{l}\text { Healthy and } \\
\text { insulin-resistant } \\
\text { mice }\end{array}$ & Mouse & $\begin{array}{l}{ }^{13} \text { C-labeled branched-chain amino } \\
\text { acids (BCAAs) infused via surgical } \\
\text { catheterization of the jugular vein or } \\
\text { administered via oral gavage }\end{array}$ & LCMS & $\begin{array}{c}\text { Quantitative framework for } \\
\text { understanding systemic BCAA } \\
\text { oxidation in mammalian systems }\end{array}$ & [37] \\
\hline $\begin{array}{l}\text { Retinal } \\
\text { degenerative } \\
\text { disease }\end{array}$ & Mouse & $\begin{array}{c}\text { Continuous }{ }^{13} \mathbf{C} \text {-proline infusions } \\
\text { through the jugular vein }\end{array}$ & $\begin{array}{l}\text { GCMS } \\
\text { LCMS }\end{array}$ & $\begin{array}{c}{ }^{13} \mathrm{C} \text { enrichment analysis to show } \\
\text { how proline catabolism in retinal } \\
\text { pigment epithelium provides } \\
\text { nutrients to fuel retinal } \\
\text { mitochondrial metabolism }\end{array}$ & [81] \\
\hline $\begin{array}{l}\text { De novo fatty } \\
\text { acid synthesis }\end{array}$ & Mouse & $\begin{array}{c}{ }^{2} \mathrm{H}_{2} \mathrm{O} \text { in drinking water. }{ }^{2} \mathrm{H} \text { labeling in } \\
\text { samples/standards determined via } \\
\text { deuterium acetone exchange }\end{array}$ & GCMS & $\begin{array}{l}\text { Incorporation of }{ }^{2} \mathrm{H} \text { label into } \\
\text { fatty acids }\end{array}$ & {$[28]$} \\
\hline $\begin{array}{l}\text { Neuronal } \\
\text { metabolism } \\
\text { during ischemic } \\
\text { stroke } \\
\end{array}$ & Mouse & {$\left[1,2-{ }^{13} C_{2}\right]$-glucose infusions } & LCMS & $\begin{array}{l}\text { Characterization of relative } \\
\text { importance of oxidative and } \\
\text { nonoxidative PPP branches }\end{array}$ & {$[38]$} \\
\hline $\begin{array}{l}\text { Cytosolic and } \\
\text { mitochondrial } \\
\text { one-carbon flux }\end{array}$ & Mouse & $\begin{array}{c}\text { Infusions of }\left[2,3,3-{ }^{2} \mathbf{H}_{3}\right] \text {-serine via } \\
\text { jugular vein catheter }\end{array}$ & LCMS & $\begin{array}{l}\text { Measurements of the source of } \\
\text { one-carbon units for purine and } \\
\text { thymidine synthesis from serine } \\
\text { by cytosolic or mitochondrial } \\
\text { folate metabolism }\end{array}$ & {$[60]$} \\
\hline $\begin{array}{l}\text { Triple-negative } \\
\text { breast cancer }\end{array}$ & Mouse & $\begin{array}{l}{ }^{13} \mathbf{C}_{16} \text {-palmitate administered via } \\
\text { intraperitoneal injection }\end{array}$ & LCMS & $\begin{array}{c}\text { Steady-state measurements of } \\
{\left[{ }^{13} \mathrm{C}\right] \text {-palmitoyl-carnitine }} \\
\text { production }\end{array}$ & {$[82]$} \\
\hline
\end{tabular}




\begin{tabular}{|c|c|c|c|c|c|}
\hline $\begin{array}{l}\text { Regulation of } \\
\text { hepatic } \\
\text { metabolism }\end{array}$ & Rat & ${ }^{13} \mathrm{C}_{16}$-palmitate infusions & GCMS & $\begin{array}{l}\text { Measurement of rates of fatty } \\
\text { acid esterification into hepatic } \\
\text { triglyceride synthesis }\end{array}$ & [83] \\
\hline $\begin{array}{l}\text { Regulation of } \\
\text { hepatic } \\
\text { gluconeogenesis }\end{array}$ & Rat & $\begin{array}{c}{ }^{13} C_{4}-\beta \text {-hydroxybutyrate infusions } \\
\text { through arterial catheter }\end{array}$ & GCMS & $\begin{array}{l}\text { Ketone body turnover used as a } \\
\text { surrogate of hepatic acetyl-CoA } \\
\text { levels to non-invasively assess } \\
\text { liver metabolism }\end{array}$ & [35] \\
\hline $\begin{array}{l}\text { Hepatic } \\
\text { mitochondrial } \\
\text { metabolism }\end{array}$ & $\begin{array}{l}\text { Rat } \\
\text { Human }\end{array}$ & $\begin{array}{c}\text { Infusions of }\left[3-{ }^{13} \mathbf{C}_{1}\right] \text {-lactate and [3- } \\
\left.{ }^{3} \mathbf{H}_{1}\right] \text {-glucose in rats (prime }+ \\
\text { continuous), and }\left[3-{ }^{13} \mathbf{C}_{1}\right] \text {-lactate and } \\
{\left[1-{ }^{13} \mathbf{C}_{1}\right] \text {-acetate in healthy humans }}\end{array}$ & $\begin{array}{l}\text { NMR } \\
\text { GCMS }\end{array}$ & $\begin{array}{l}\text { Hepatic mitochondrial fluxes in } \\
\text { various physiological and } \\
\text { pathophysiological states }\end{array}$ & [50] \\
\hline $\begin{array}{l}\text { Metabolic } \\
\text { homeostasis } \\
\text { during } \\
\text { starvation }\end{array}$ & Rat & $\begin{array}{c}\text { Infusions (prime }+ \text { continuous) of }{ }^{13} \mathbf{C}_{16-} \\
\text { palmitate, }{ }^{13} \mathbf{C}_{4}-\boldsymbol{\beta} \text {-hydroxybutyrate } \\
\text { and }{ }^{2} \mathbf{H}_{5}-\text { glycerol through a carotid } \\
\text { artery catheter }\end{array}$ & GCMS & $\begin{array}{l}\text { Shift from glucose to fat/ketone } \\
\text { metabolism in mammals under } \\
\text { nutrient starvation }\end{array}$ & [34] \\
\hline $\begin{array}{l}\text { Hepatic } \\
\text { mitochondrial } \\
\text { metabolism } \\
\text { during insulin } \\
\text { resistance } \\
\end{array}$ & Mouse & $\begin{array}{c}\text { Infusions of }\left[3,4-{ }^{13} C_{2}\right] \text {-glucose, }{ }^{13} C_{4-} \\
\text { sodium } \beta \text {-hydroxybutyrate, }[3,4- \\
\left.{ }^{13} C_{2}\right] \text {-acetoacetate, and }{ }^{13} C_{3-} \\
\text { propionate via surgical indwelling } \\
\text { catheterization of the jugular vein } \\
\end{array}$ & LCMS & $\begin{array}{l}\text { In vivo fluxes through } \\
\text { mitochondrial metabolic } \\
\text { pathways }\end{array}$ & [84] \\
\hline $\begin{array}{l}\text { Metabolic } \\
\text { syndrome }\end{array}$ & Mouse & $\begin{array}{l}{ }^{13} \mathbf{C}_{6} \text {-fructose infused via jugular vein } \\
\text { catheter or administered via oral gavage }\end{array}$ & LCMS & $\begin{array}{c}\text { Quantitative assessment of } \\
\text { fructose catabolism in different } \\
\text { organs }\end{array}$ & [27] \\
\hline \multicolumn{6}{|c|}{ Multiple Tracers } \\
\hline $\begin{array}{l}\text { Non-small cell } \\
\text { lung cancer }\end{array}$ & $\begin{array}{l}\text { Human } \\
\text { Mouse }\end{array}$ & $\begin{array}{c}{ }^{13} C_{6} \text {-glucose, }{ }^{13} C_{3} \text {-lactate and }\left[2-{ }^{13} C_{1}\right]- \\
\text { lactate infusions before surgical tumor } \\
\text { resection }\end{array}$ & GCMS & $\begin{array}{c}\text { Contributions of glucose/lactate } \\
\text { to lung tumor metabolism based } \\
\text { on }{ }^{13} \mathrm{C} \text { enrichments }\end{array}$ & [20] \\
\hline $\begin{array}{l}\text { Turnover fluxes } \\
\text { of circulating } \\
\text { metabolites }\end{array}$ & Mouse & $\begin{array}{c}\text { Infusions of }{ }^{13} \mathbf{C}_{6} \text { - glucose, }{ }^{13} \mathbf{C}_{5-} \\
\text { glutamine, }{ }^{13} \mathbf{C}_{3} \text {-lactate, }{ }^{13} \mathbf{C}_{16^{-}} \\
\text {palmitate and other tracers through } \\
\text { venous catheter }\end{array}$ & $\begin{array}{l}\text { LCMS } \\
\text { GCMS }\end{array}$ & $\begin{array}{l}\text { Determination of circulatory } \\
\text { turnover fluxes of various } \\
\text { metabolites via analysis of serum } \\
\text { and tissue samples combined } \\
\text { with whole-body modeling }\end{array}$ & [51] \\
\hline $\begin{array}{c}\text { Fate of nutrients } \\
\text { in lung tumor vs } \\
\text { normal lung } \\
\text { tissue } \\
\end{array}$ & Mouse & $\begin{array}{c}\text { Infusions of }{ }^{13} \mathbf{C}_{6}-\text { glucose, }{ }^{13} \mathbf{C}_{5-} \\
\text { glutamine and }\left[1-{ }^{13} C_{1}\right]-\text { pyruvate via } \\
\text { surgical catheterization of the jugular } \\
\text { vein and/or carotid artery }\end{array}$ & $\begin{array}{l}\text { LCMS } \\
\text { GCMS }\end{array}$ & $\begin{array}{c}\text { Fate of glucose/glutamine in } \\
\text { tumors in vivo, and how this is } \\
\text { modulated by cell-extrinsic } \\
\text { factors }\end{array}$ & [19] \\
\hline $\begin{array}{l}\text { Glioblastomas } \\
\text { and brain } \\
\text { metastases }\end{array}$ & Mouse & $\begin{array}{l}{ }^{13} \mathrm{C}-\mathrm{NMR} \text { analysis of brain tumors } \\
\text { resected from patients during infusion } \\
\text { of }\left[\mathbf{1}, \mathbf{6 -}{ }^{\mathbf{1 3}} \mathrm{C}_{\mathbf{2}}\right] \text {-glucose, }\left[\mathbf{1}, \mathbf{2 -}-{ }^{13} \mathbf{C}_{\mathbf{2}}\right]- \\
\text { acetate and }{ }^{13} \mathbf{C}_{\mathbf{5}} \text {-glutamine }\end{array}$ & NMR & $\begin{array}{l}\text { Nutrient utilization based on the } \\
\text { enrichment of relevant nutrient } \\
\text { pools in plasma and tissues }\end{array}$ & [39] \\
\hline $\begin{array}{l}\text { Liver } \\
\text { metabolism }\end{array}$ & Mouse & $\begin{array}{l}\text { Combination of infusions (via jugular } \\
\text { vein catheters) and perfusions of } \\
\text { multiple tracers including }{ }^{2} \mathrm{H}_{2} \mathrm{O} \text { and }{ }^{13} \mathrm{C} \text { - } \\
\text { glucose/propionate/pyruvate/lactate }\end{array}$ & NMR & $\begin{array}{c}\text { Role of anaplerosis via pyruvate } \\
\text { carboxylase in sustaining hepatic } \\
\text { function }\end{array}$ & [85] \\
\hline $\begin{array}{l}\text { High fat diet- } \\
\text { induced obesity }\end{array}$ & Mouse & $\begin{array}{c}\text { Intraperitoneal injections of }{ }^{13} C_{3} \text {-lactate } \\
\text { and }{ }^{13} C_{3} \text {-pyruvate }\end{array}$ & $\begin{array}{l}\text { GCMS } \\
\text { LCMS }\end{array}$ & $\begin{array}{l}\text { Contribution of the mitochondrial } \\
\text { pyruvate carrier to hyperglycemia } \\
\text { and altered hepatic TCA cycle } \\
\text { metabolism during high fat diet }\end{array}$ & [86] \\
\hline $\begin{array}{l}\text { Liver metabolic } \\
\quad \text { fluxes }\end{array}$ & Mouse & $\begin{array}{l}\text { Combined infusions of }\left[6,6-{ }^{2} \mathbf{H}_{2}\right]- \\
\text { glucose, }{ }^{2} \mathrm{H}_{2} \mathbf{O} \text { and }{ }^{13} \mathbf{C}_{3} \text {-propionate via } \\
\text { jugular vein catheter and sampling from } \\
\text { left carotid artery }\end{array}$ & GCMS & $\begin{array}{c}\text { Flux analysis to quantify hepatic } \\
\text { glucose and intermediary fluxes } \\
\text { during physiological stress }\end{array}$ & [49] \\
\hline $\begin{array}{l}\text { Whole-body } \\
\text { metabolism }\end{array}$ & $\begin{array}{l}\text { Mouse } \\
\text { Pig }\end{array}$ & $\begin{array}{c}\text { Infusions of multiple tracers including } \\
{ }^{13} C_{6} \text {-glucose, }{ }^{13} C_{3} \text {-lactate, }{ }^{13} C_{6} \text {-citrate, } \\
{ }^{13} C_{4} \text {-malate, }{ }^{13} C_{5} \text {-succinate, and }{ }^{13} C_{2}- \\
\text { acetate via surgical jugular vein } \\
\text { catheterization (in mice only) }\end{array}$ & LCMS & $\begin{array}{l}\text { Organ-specific nutrient usage } \\
\text { and inter-organ nutrient } \\
\text { exchange based on differences in } \\
\text { arterial/venous metabolite levels } \\
\text { (pigs) and } 13 \mathrm{C} \text { enrichment (mice) }\end{array}$ & [40] \\
\hline
\end{tabular}




\section{Text Box 1 - Important Considerations when Measuring Cellular Metabolism in vivo}

Irrespective of the approach chosen for tracer administration and measurement, some important considerations must always be followed when performing stable-isotope measurements (or, in general, any metabolic measurements) in vivo in order to ensure these measurements are reproducible and representative of the biological question being addressed.

First, experimental conditions must always be standardized and controlled at different levels to maintain biological reproducibility between measurements. In this sense, maintenance of physiological conditions and monitorization of diet composition and feeding/fasting protocols is crucial during in vivo tracer administration. The timing of feeding/fasting should be strictly controlled, as multiple studies have demonstrated how metabolism is regulated by the circadian clock [87-89], and how in turn the circadian rhythm is affected by metabolic changes [90,91], including those induced by feeding/fasting themselves $[92,93]$. In addition, it is fundamental to control the generation of stress conditions that could induce metabolic alterations during the measurements. This can be achieved by reducing where possible the manipulation of the experimental models before and during sampling [94] and by controlling animal housing conditions [95]. Infusions can be performed both in anesthetized and conscious animals, and in both cases stress control is critical to minimize metabolic changes. Specifically for the first case, the metabolic response to anesthesia needs to be considered [96], since volatile (e.g. isoflurane) or intravenous (e.g. propofol) anesthetics can lead to distinct metabolic alterations $[97,98]$.

Second, during tissue/blood extraction, it is fundamental to minimize the processing time and maintain samples cold to guarantee a stable extract representative of the biological specimen's metabolome at the time of harvesting. For tissue specimens, snap-freezing (or quenching) of the samples before extraction is recommended. Quenching is particularly important for specimens with highly active metabolism, such as proliferating cells and tissues [99]. Tissues can then be stored at $-80^{\circ} \mathrm{C}$, and afterwards pulverized and extracted with appropriate cold organic solvents [21]. In general, different solvents will optimally extract different chemical classes of metabolites [79], but labeling should not be affected by the choice of solvent as long as the measurement detection limit is not reached.

Finally, the nature of the samples and the goal of the study will determine the choice of the specific platform for the quantification of the tracer incorporation into downstream metabolites. A wide range of analytical techniques can be used for this purpose [100], with nuclear magnetic resonance (NMR) spectroscopy and mass spectrometry (MS) being the most widely adopted (Table 1). In some cases, a combination of various approaches can be adopted to increase the coverage of the data [101,102]. 


\section{Text Box 2 - Understanding MDVs: The Keystone of Stable-Isotope Measurements}

Interpreting stable-isotope measurements requires defining measurable quantities that reflect the incorporation of label from the fed tracer into downstream metabolites, and the most frequently used are mass-distribution vectors (MDVs) [14]. To understand MDVs, one must first introduce the concept of an isotopologue. In the context of a stable-isotope experiment, an isotopologue (also known as mass isotopomer) represents an instance of a metabolite that carries a defined number of tracer-labeled atoms, irrespective of their position within the metabolite backbone. In this context, MDVs are vectors of the form

$$
\vec{X}=\left\{X_{0}, X_{1}, \ldots, X_{N}\right\}
$$

where each component $X_{j}$ (with $j=0,1, \ldots, N$ ) represents the fraction of a metabolite's pool that corresponds to the $j^{\text {th }}$ labeled isotopologue (i.e. carrying exactly $j$ tracer-labeled atoms, regardless of their position), and $N$ is the maximum number of labeled atoms that the metabolite can incorporate. For instance, in the case of ${ }^{13} \mathrm{C}$-labeled pyruvate, $N=3$ (since a pyruvate molecule has three carbon atoms where ${ }^{13} \mathrm{C}$-label can be incorporated), and $X_{1}=$ 0.2 would indicate that $20 \%$ of the total pyruvate pool carries exactly one ${ }^{13} \mathrm{C}$-labeled carbon (without distinction as to whether this ${ }^{13} \mathrm{C}$-incorporation happened in the first/second/third carbon within pyruvate's backbone). The components $X_{j}$ are known as fractional isotopologue enrichments, and their sum must equal 1 (i.e. $\sum_{j=0}^{N} X_{j}=1$ ), since this must account for $100 \%$ of the metabolite pool. Often, the components $X_{j}$ are alternatively denoted as $X_{M+j}$, given that for most commonly used stable isotopes (e.g. ${ }^{13} \mathrm{C} /{ }^{2} \mathrm{H} /{ }^{15} \mathrm{~N}$ ) the incorporation of $j$ labeled atoms into a metabolite will yield a mass shift of $j$ atomic units relative to the nominal mass $\mathrm{M}$ of the unlabeled metabolite.

Specific approaches for determining MDVs depend on the analytical technique used for sample measurement. Here, we exemplify this based on GC-MS measurements (Figure I). GC-MS allows identifying chromatographic peaks corresponding to specific metabolites, and separates the contributions of different isotopologues to those peaks based on the known isotopologue masses (e.g. in the case of TBDMS-derivatized ${ }^{13} \mathrm{C}$-labeled pyruvate, these range from $174 \mathrm{Da}$ for the unlabeled isotopologue, up to $177 \mathrm{Da}$ for a triply-substituted isotopologue). The areas under those peaks $\left(I C_{j}\right)$ represent the measured ion counts for each isotopologue, and their sum $\left(T C=\sum_{j=0}^{N} I C_{j}\right)$ the total counts for the metabolite (left panel). From them, a measured MDV ( $\vec{X}_{m}$, center panel) can be determined as

$$
\vec{X}_{m}=\left\{X_{m 0}, X_{m 1}, \ldots, X_{m N}\right\} \quad X_{m j}=\frac{I C_{j}}{T C}(j=0,1, \ldots, N)
$$

Measured MDVs are, however, not directly representative of actual label incorporation, since signal at isotopologue masses $j \geq 1$ will be contributed not only by incorporation of tracer label (e.g. ${ }^{13} \mathrm{C}$ ), but also by the natural occurrence of stable isotopes of all atoms within the metabolite (e.g. for TBDMS-derivatized pyruvate, all of ${ }^{13} \mathrm{C} /{ }^{2} \mathrm{H} /{ }^{18} \mathrm{O} /{ }^{15} \mathrm{~N} /{ }^{29} \mathrm{Si} /{ }^{30} \mathrm{Si}$ ). Accounting for natural abundances is particularly important when data interpretation relies on quantification of $j=1$ isotopologues (where natural-abundance bias will generally be maximum), and also when using derivatization agents during sample preparation (since these will contribute additional atoms to the measured metabolites, increasing the bias). As emphasized in the literature [14,103], natural abundances should not be corrected by simply subtracting the MDVs of unlabeled metabolite standards, but rather considering a combination of the theoretical MDVs for all potentially labeled isotopologues of a metabolite. This approach, implemented in available software packages (e.g. [104]), implies solving a linear system of equations

$$
\vec{X}_{m}=\vec{X} \cdot \overline{\bar{L}}
$$

where $\vec{X}_{m}$ and $\vec{X}$ are the measured and actual MDVs for a metabolite, and the $j^{\text {th }}$ row of the matrix $\bar{L}$ contains the theoretically predicted MDV for the $j^{\text {th }}$ labeled isotopologue (i.e. based on natural abundance of all atoms when $j$ of them are fixed, labeled atoms). Only once the actual MDVs $\vec{X}$ have been determined (right panel), data interpretation can proceed (Text Boxes 3, 4). 

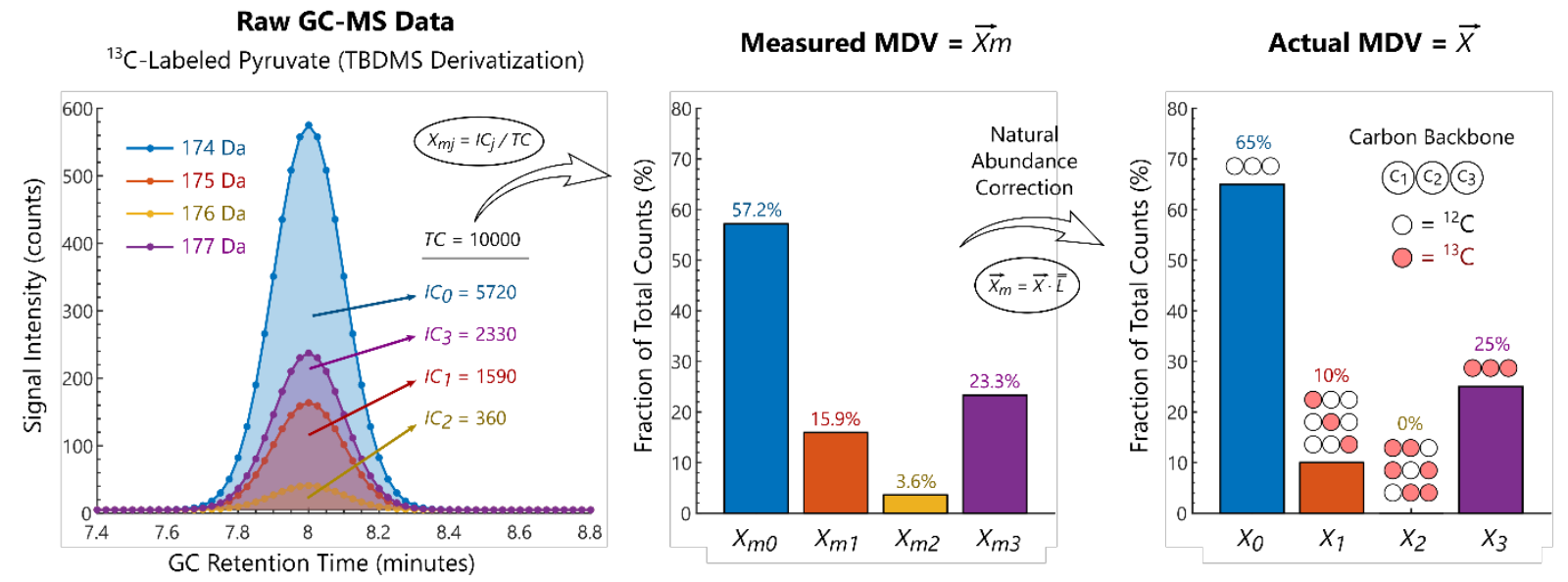

Text Box 2 Figure I. Determination of MDVs from measured experimental data. The figure shows an example based on ${ }^{13} \mathrm{C}$-labeled pyruvate measured by GC-MS after TBDMS derivatization. Ion counts for different isotopologues $\left(I C_{j}\right)$ are determined by adding up signal intensities under mass-selected chromatographic peaks corresponding to the known isotopologue masses (left panel), after which a measured $\operatorname{MDV}\left(\vec{X}_{m}\right)$ is determined by dividing each of these ion counts by the total counts (TC) considering all isotopologues (center panel). The measured MDV is finally converted into an actual MDV $(\vec{X})$ by appropriately correcting for the contributions of naturally occurring isotopes of the different atoms in pyruvate and TBDMS (right panel), after which data interpretation can proceed. 


\section{Text Box 3 - Interpreting in vivo Tracer Measurements (1): Pathway Activities and Nutrient Turnover Rates}

Here and in Text Box 4, we use worked examples based on the literature to illustrate three useful, complementary approaches for interpreting in vivo tracer measurements based solely on MDV analysis, allowing to obtain qualitative and/or quantitative readouts of in vivo metabolism without resorting to complex metabolic models or computations.

Pathway Activities: given a judicious tracer selection and experimental design, simple MDV inspection can generally provide valuable information about the activities of different metabolic pathways in specific tissues. An example can be found in [27], where mice were alternatively gavaged with ${ }^{13} C_{3}$-fructose tracers positionally-labeled in either the first/last three carbon atoms, to assess the metabolism of ingested fructose by the small intestine (Figure I, left panel). It is known that fructose catabolism splits its carbon backbone at the level of fructose-1phosphate, with the first/last three carbons yielding respectively dihydroxyacetone-phosphate (DHAP) and glyceraldehyde. Both DHAP and glyceraldehyde can be further converted into glyceraldehyde-phosphate (GAP), whereas glyceraldehyde can alternatively produce glycerate, both of which can serve as substrate for further organic-acid production. Thus, by comparing the relative ${ }^{13} \mathrm{C}$-enrichments measured in circulating organic acids resulting from the administration of either tracer, the authors could gauge the relative contributions of these alternative pathways towards organic acid production, concluding that the glycerate contribution is dominant.

Turnover Rates: in tracer infusion experiments, MDV analysis allows also a direct quantification of whole-body nutrient turnover rates (i.e. the rates at which a whole organism jointly consumes/produces specific nutrients to maintain homeostasis) (Figure I, right panel). These can be inferred simply by continuously infusing a fully-labeled tracer of the nutrient of interest into the bloodstream, and monitoring the ensuing plasma enrichment of that nutrient. Once a steady enrichment is achieved, the turnover rate $T$ of the nutrient will be given by $[34,51]$

$$
T=R \times\left(\frac{X_{N, \text { tracer }}}{X_{N, \text { plasma }}}-1\right)
$$

where $R$ is the tracer infusion rate, $X_{N, \text { plasma }}$ the steady-state fractional arterial plasma enrichment of the fullylabeled nutrient isotopologue, and $X_{N, \text { tracer }}$ its corresponding fractional enrichment in the infusate (which accounts for tracer impurities). For instance, suppose a $500 \mathrm{mM}$ solution of a ${ }^{13} \mathrm{C}_{6}$-glucose tracer with $99 \%$ atomic purity (hence a ${ }^{13} \mathrm{C}_{6}$ fractional enrichment $X_{6 \text {,tracer }}=(0.99)^{6} \approx 0.94$ ) was infused intravenously into a subject at a constant rate of $0.05 \mu \mathrm{L} / \mathrm{g} / \mathrm{min}$ (corresponding to a tracer infusion rate $R=500 \times 0.05=25 \mathrm{nmol} / \mathrm{g} / \mathrm{min}$ ). If, upon reaching steady state, a $15 \%$ enrichment of ${ }^{13} \mathrm{C}_{6}$-glucose was measured in the plasma $\left(X_{6, \text { plasma }}=0.15\right)$, then one could estimate the subject's whole-body glucose turnover rate as

$$
T_{\text {glucose }}=25 \times\left(\frac{0.94}{0.15}-1\right) \approx 132 \mathrm{nmol} / \mathrm{g} / \mathrm{min}
$$




\section{Pathway Activities}

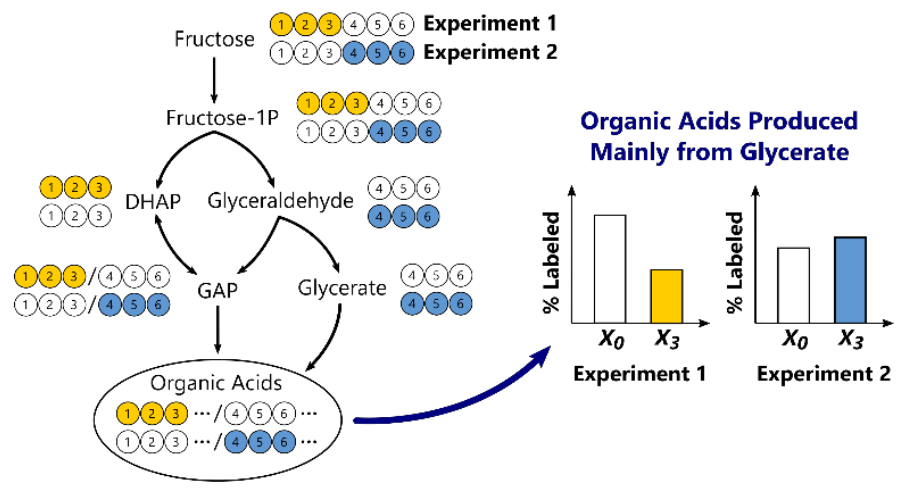

Nutrient Turnover Rates

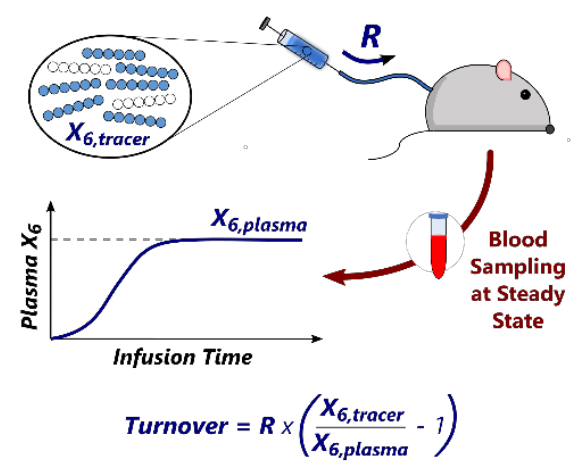

Text Box 3 Figure I. Interpretation of in vivo tracer measurements: pathway activities and nutrient turnovers.

Left panel: ${ }^{13} \mathrm{C}_{3}$-fructose tracers positionally-labeled in either the first/last three carbon atoms were orally administered to mice in two separate experiments in [27]. The relative contributions of the two known modes of intestinal fructose catabolism to organic acids (via GAP or glycerate) were then assessed by comparing the resulting ${ }^{13} \mathrm{C}$-enrichment in circulating organic acids between both experiments. Right panel: schematic of how continuous infusions of uniformly-labeled tracers can be used to quantitatively determine whole-body nutrient turnover rates, based simply on the tracer infusion rate, the tracer purity, and the ensuing steady-state enrichment in arterial plasma. 


\section{Text Box 4 - Interpreting in vivo Tracer Measurements (2): Fractional Nutrient Contributions}

In particular cases, MDV analysis allows quantifying the contributions of specific nutrient sources towards the generation of metabolic products within a tissue. For instance, under isotopic steady-state, and when the source of interest $(S)$ is the only labeled nutrient in the bloodstream, the fraction of a metabolic product $(P)$ originating from it in a specific tissue, $F C_{S \rightarrow P}$, can be inferred from the MDVs of the product $\left(\vec{X}_{P}\right.$, in the tissue) and source $\left(\vec{X}_{S}\right.$, in the bloodstream), by extending an approach widely used in vitro [14] to account for in vivo tracer dilution [51,105]

$$
F C_{S \rightarrow P}=\frac{A P E\left(\vec{X}_{P}\right)}{A P E\left(\vec{X}_{S}\right)}, \quad \text { with } \quad A P E(\vec{X})=\frac{1}{N} \times \sum_{j=0}^{N} j \cdot X_{j}=\frac{X_{1}+2 X_{2}+\cdots+N X_{N}}{N}
$$

Here, $F C_{S \rightarrow P}$ represents the fraction of $P$ made from $S$, and $A P E$ the so-called atomic percent enrichment (the fraction of the total potentially-labeled atomic pool in source/product that is actually labeled). The assumption of a single labeled source is, nevertheless, often not satisfied in vivo, since inter-organ exchanges will generally lead to multiple labeled species in the bloodstream, even when administering a single tracer. This issue can, however, be sometimes tackled by administration of judiciously chosen tracers, as illustrated in [20] based on short ${ }^{13} C_{6}$-glucose $+\left[3-{ }^{13} C_{1}\right]-$ lactate co-infusions. Indeed, since these tracers yield distinct labeling patterns in TCA-cycle intermediates, comparing the appropriate isotopologue enrichments of such intermediates to those in glucose/lactate allowed the authors to qualitatively assess the relative importance of lactate/glucose contributions to TCA-cycle carbon in murine lung tumors, identifying lactate as the major contributor of the two (Figure I, left panel). Interestingly, this idea can be generalized into a simple, more quantitative approach, building on the framework of isotopicallystationary MFA. Indeed, if $S_{1}, S_{2}, \cdots, S_{Q}$ denote all potential sources of a product $P$ within a tissue, with $\vec{X}_{S_{i}}$ denoting the measured tissue-MDV of $S_{i}$, and $\vec{Y}_{S_{i}}$ the hypothetical MDV that $P$ would have if $S_{i}$ was the only source contributing to it, then the measured tissue-MDV of $P$ should satisfy

$$
\vec{X}_{P}=\sum_{i=1}^{Q} \vec{Y}_{S_{i}} \cdot F C_{S_{i} \rightarrow P}=\vec{Y}_{S_{1}} \cdot F C_{S_{1} \rightarrow P}+\vec{Y}_{S_{2}} \cdot F C_{S_{2} \rightarrow P}+\cdots+\vec{Y}_{S_{Q}} \cdot F C_{S_{Q} \rightarrow P}
$$

This constitutes a linear system of $N+1$ equations (one per component of $\vec{X}_{P}$ ) with the contributions from each source $\left(F C_{S_{i} \rightarrow P}\right)$ as unknowns, and can thus be solved for the latter if (i) only up to $N$ labeled sources of $P$ (plus one pooling all unlabeled sources together) are considered, and (ii) the MDVs $\left(\vec{Y}_{S_{i}}\right)$ contributed to $P$ by each of them are linearly independent, which can again be attained by judicious tracer selection. A worked example for pyruvate is shown below based on data similar to that in [20] (Figure I, right panel), illustrating how to determine the $\vec{Y}_{S_{i}}$ 's from the known MDVs of the various sources considered. 


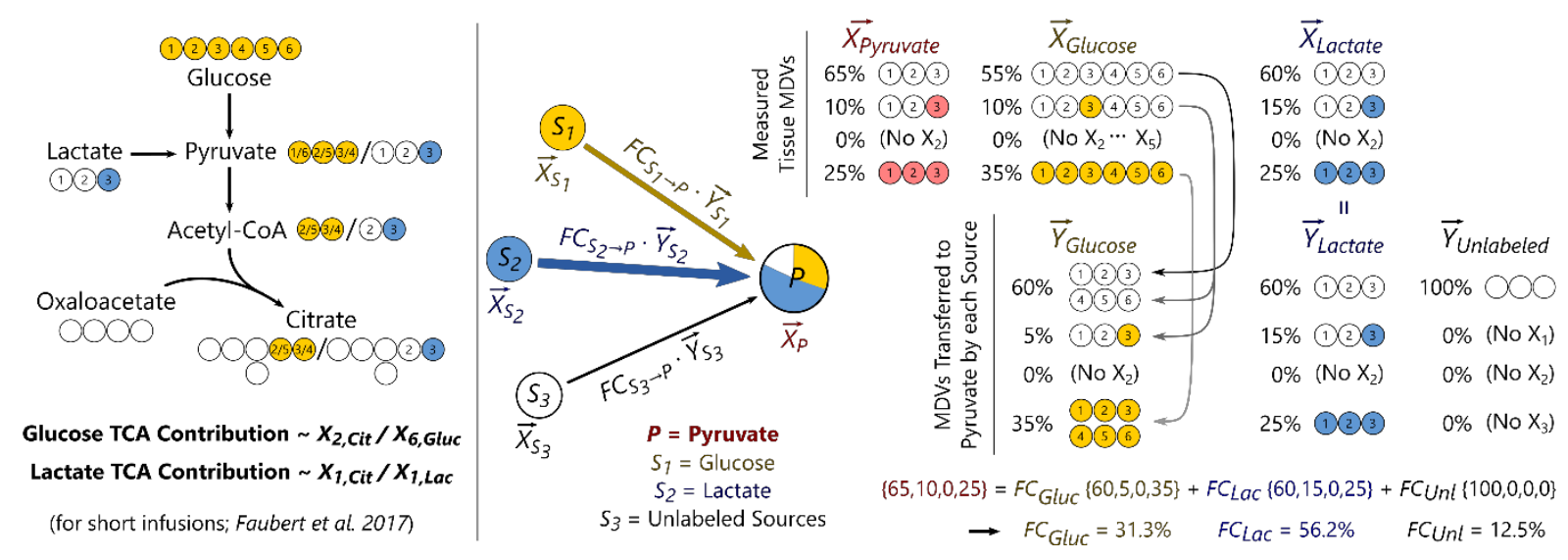

Text Box 4 Figure I. Interpretation of in vivo tracer measurements: nutrient contributions. Left panel: simultaneous co-infusions of ${ }^{13} \mathrm{C}_{6}$-glucose $+\left[{ }^{3}-{ }^{13} \mathrm{C}_{1}\right]$-lactate were used in [20] to evaluate the relative contributions of glucose and lactate to TCA-cycle carbon in murine lung tumors, based on the known distinct enrichment profiles ensuing from either tracer in short infusions. Right panel: schematic on how the same idea can be generalized into a quantitative approach, based on steady-state measurements of tissue MDVs for the nutrient sources and product of interest, and a knowledge of the label-transfer patterns from these different sources to the product. 


\section{GLOSSARY}

Central Carbon Metabolism: the set of metabolic pathways responsible for transforming carbon from nutrients into biomass and energy inside the cell, including glycolysis, gluconeogenesis, the pentose phosphate pathway, the TCA cycle, the glyoxylate shunt, and the methyl-citrate cycle.

Gas Chromatography (GC): analytical chromatographic technique used to separate volatile substances in the gas phase, based on their different interactions with a stationary phase (or column). The mobile phase is not involved in the interactions per se, but is rather a chemically inert gas that serves to carry the molecules through the stationary phase.

High-Resolution Mass Spectrometry (HR-MS): collection of MS techniques capable of high resolution in $(\mathrm{m} / \mathrm{z})$, typically characterized by an accuracy of four or more decimal places, allowing the detection of differences in mass between compounds with the same nominal mass but different chemical formulas.

Isotopic Steady State: a condition during an isotope-labeling experiment in which the isotopic enrichment in a given metabolite is stable over time. This should not be confused with the term metabolic steady state, representing a condition in which all layers of metabolism (i.e., metabolite concentrations and metabolic fluxes) remain constant over time in a biological system, irrespective of isotopic labeling.

Isotopologues: instances of the same molecule that differ in their isotope composition (and consequently in mass). Isotopologues are often referred to in the literature as mass isotopomers. The use of the latter term is however discouraged, as it may lead to incorrect identification with the term isotopomer itself (see below).

Isotopomers: instances of the same isotopologue that differ in the position of their isotopes (and thus not in mass). Resolving the different isotopomers of a given isotopologue requires analytical techniques capable of distinguishing positional isotopic enrichment, such as nuclear magnetic resonance.

Liquid Chromatography (LC): analytical chromatographic technique used to separate ions or molecules based on their different interactions with a liquid mobile phase (where sample ions or molecules are dissolved) and a solid stationary phase (or column).

Mass Distribution Vector (MDV): in an isotope labeling experiment, a vector representing the fractional abundances of different isotopologues of a given metabolite in a sample, originating from label incorporation, relative to the total pool of that metabolite in the sample. For a metabolite with $N$ atoms susceptible of labeling incorporation, the corresponding MDV will have $N+1$ components, ranging from the unlabeled isotopologue (no label incorporation) to the fully-labeled isotopologue (maximum label incorporation).

Mass Spectrometry (MS): analytical technique to measure the mass-to-charge ratio $(\mathrm{m} / \mathrm{z})$ of one or more ionized molecular species present in a sample.

Mass Spectrometry Imaging (MSI): MS-based technique used to determine the spatial abundance profiles of different molecular species within a 2-dimensional tissue or sample.

Nutrient Turnover Rate: the rate at which a whole organism jointly consumes (or produces) a given nutrient to maintain whole-body metabolic homeostasis.

Stable-Isotope Tracer: a molecule in which one or more atoms are substituted by heavy stable (i.e. nonradioactive) isotopes of the same chemical element. The labeled atoms will generally present the same biological behavior as their unlabeled counterparts, but their increased mass enables their distinction from the latter by appropriate analytical techniques. 


\section{REFERENCES}

1 Lorendeau, D. et al. (2015) Metabolic Control of Signalling Pathways and Metabolic Auto-Regulation. Biol. Cell 107, 251-272

Rinaldi, G. et al. (2018) Metabolic Interactions in Cancer: Cellular Metabolism at the Interface Between the Microenvironment, the Cancer Cell Phenotype and the Epigenetic Landscape. Wiley Interdiscip. Rev. Syst. Biol. Med. 10, e1397

Gomes, A.P. and Blenis, J. (2015) A Nexus for Cellular Homeostasis: The Interplay Between Metabolic and Signal Transduction Pathways. Curr. Opin. Biotechnol. 34, 110-117

Metallo, C.M. and Vander Heiden, M.G. (2013) Understanding Metabolic Regulation and Its Influence on Cell Physiology. Mol. Cell 49, 388-398

Vander Heiden, M.G. and DeBerardinis, R.J. (2017) Understanding the Intersections between Metabolism and Cancer Biology. Cell 168, 657-669

Elia, I. et al. (2016) Organ-Specific Cancer Metabolism and Its Potential for Therapy. In Metabolic Control 233 (Herzig, S., ed), pp. 321-353, Springer International Publishing Jang, C. et al. (2018) Metabolomics and Isotope Tracing. Cell 173, 822-837

10 Elia, I. and Fendt, S.-M. (2016) In Vivo Cancer Metabolism is Defined by the Nutrient Microenvironment. Transl. Cancer Res. 5, S1284-S1287

Faubert, B. and DeBerardinis, R.J. (2017) Analyzing Tumor Metabolism In Vivo. Annu. Rev. Cancer Biol. 1, 99-117

Sivitz, W.I. (2017) Techniques to Investigate Bioenergetics of Mitochondria. In Techniques to Investigate Mitochondrial Function in Neurons 123 (Strack, S. and Usachev, Y. M., eds), pp. 67-94, Springer New York

Chen, W.W. et al. (2016) Absolute Quantification of Matrix Metabolites Reveals the Dynamics of Mitochondrial Metabolism. Cell 166, 1324-1337

Buescher, J.M. et al. (2015) A Roadmap for Interpreting 13C Metabolite Labeling Patterns from Cells. Curr. Opin. Biotechnol. 34, 189-201

Srivastava, A. et al. (2016) Strategies for Extending Metabolomics Studies with Stable Isotope Labelling and Fluxomics. Metabolites 6, 32

Bruntz, R.C. et al. (2017) Exploring Cancer Metabolism Using Stable Isotope-Resolved Metabolomics (SIRM). J. Biol. Chem. 292, 11601-11609

Chung, Y.-H. et al. (2017) Early Response Monitoring Following Radiation Therapy by Using [18F]FDG and [11C]Acetate PET in Prostate Cancer Xenograft Model with Metabolomics Corroboration. Molecules 22, 1946

Lord, S.R. et al. (2018) Integrated Pharmacodynamic Analysis Identifies Two Metabolic Adaption Pathways to Metformin in Breast Cancer. Cell Metab. 28, 679-688

Davidson, S.M. et al. (2016) Environment Impacts the Metabolic Dependencies of Ras-Driven Non-Small Cell Lung Cancer. Cell Metab. 23, 517-528

Faubert, B. et al. (2017) Lactate Metabolism in Human Lung Tumors. Cell 171, 358-371

Broekaert, D. and Fendt, S.M. (2019) Measuring In Vivo Tissue Metabolism Using 13C Glucose Infusions in Mice. In Metabolic Signaling 1862 (Fendt, S.-M. and Lunt, S. Y., eds), pp. 67-82, Humana Press

Sun, R.C. et al. (2017) Noninvasive Liquid Diet Delivery of Stable Isotopes into Mouse Models for Deep Metabolic Network Tracing. Nat. Commun. 8, 1646

Kim, I.-Y. et al. (2016) Applications of Stable, Nonradioactive Isotope Tracers in in vivo Human Metabolic Research. Exp. Mol. Med. 48, e203 
Marin-Valencia, I. et al. (2012) Analysis of Tumor Metabolism Reveals Mitochondrial Glucose Oxidation in Genetically Diverse Human Glioblastomas in the Mouse Brain in vivo. Cell Metab. 15, 827-837

Sellers, K. et al. (2015) Pyruvate Carboxylase is Critical for Non-Small-Cell Lung Cancer Proliferation. J. Clin. Invest. 125, 687-698

Jang, C. et al. (2018) The Small Intestine Converts Dietary Fructose into Glucose and Organic Acids. Cell Metab. 27, 351-361

Svensson, R.U. et al. (2016) Inhibition of Acetyl-CoA Carboxylase Suppresses Fatty Acid Synthesis and Tumor Growth of Non-Small-Cell Lung Cancer in Preclinical Models. Nat. Med. 22, 1108-1119

Antoniewicz, M.R. (2013) 13C Metabolic Flux Analysis: Optimal Design of Isotopic Labeling Experiments. Curr. Opin. Biotechnol. 24, 1116-1121

Crown, S.B. et al. (2012) Rational Design of 13C-labeling Experiments for Metabolic Flux Analysis in Mammalian Cells. BMC Syst. Biol. 6, 43

Metallo, C.M. et al. (2009) Evaluation of 13C Isotopic Tracers for Metabolic Flux Analysis in Mammalian Cells. J. Biotechnol. 144, 167-174

Christen, S. et al. (2016) Breast Cancer-Derived Lung Metastases Show Increased Pyruvate CarboxylaseDependent Anaplerosis. Cell Rep. 17, 837-848

Wang, Y. et al. (2018) Uncoupling Hepatic Oxidative Phosphorylation Reduces Tumor Growth in Two Murine Models of Colon Cancer. Cell Rep. 24, 47-55

Perry, R.J. et al. (2018) Leptin Mediates a Glucose-Fatty Acid Cycle to Maintain Glucose Homeostasis in Starvation. Cell 172, 234-248 756

Davidson, S.M. et al. (2017) Direct Evidence for Cancer-Cell-Autonomous Extracellular Protein Catabolism in Pancreatic Tumors. Nat. Med. 23, 235-241

Neinast, M.D. et al. (2019) Quantitative Analysis of the Whole-Body Metabolic Fate of Branched-Chain Amino Acids. Cell Metab. 29, 417-429

Quaegebeur, A. et al. (2016) Deletion or Inhibition of the Oxygen Sensor PHD1 Protects against Ischemic Stroke via Reprogramming of Neuronal Metabolism. Cell Metab. 23, 280-291

Mashimo, T. et al. (2014) Acetate Is a Bioenergetic Substrate for Human Glioblastoma and Brain Metastases. Cell 159, 1603-1614

Jang, C. et al. (2019) Metabolite Exchange between Mammalian Organs Quantified in Pigs. Cell Metab. 30, 594-606

Antoniewicz, M.R. (2018) A Guide to 13C Metabolic Flux Analysis for the Cancer Biologist. Exp. Mol. Med. 50,19

Nilsson, R. and Jain, M. (2016) Simultaneous Tracing of Carbon and Nitrogen Isotopes in Human Cells. Mol. Biosyst. 12, 1929-1937

Trötzmüller, M. et al. (2017) Determination of the Isotopic Enrichment of 13C-and 2H-Labeled Tracers of Glucose Using High-Resolution Mass Spectrometry: Application to Dual- and Triple-Tracer Studies. Anal. Chem. 89, 12252-12260

Yang, Y. et al. (2017) Chloroformate Derivatization for Tracing the Fate of Amino Acids in Cells and Tissues by Multiple Stable Isotope Resolved Metabolomics (mSIRM). Anal. Chim. Acta 976, 63-73

Sauer, U. (2006) Metabolic Networks in Motion: 13C-based Flux Analysis. Mol. Syst. Biol. 2, 62

Nielsen, J. (2003) It Is All about Metabolic Fluxes. J. Bacteriol. 185, 7031-7035

47 Niedenführ, S. et al. (2015) How to Measure Metabolic Fluxes: A Taxonomic Guide for $13 C$ Fluxomics. Curr. Opin. Biotechnol. 34, 82-90 
Study Metabolism in Perfused Working Hearts. Am. J. Physiol. Circ. Physiol. 311, H881-H891

Hasenour, C.M. et al. (2015) Mass Spectrometry-Based Microassay of 2H and 13C Plasma Glucose Labeling to Quantify Liver Metabolic Fluxes in vivo. Am. J. Physiol. Metab. 309, E191-E203

Perry, R.J. et al. (2017) Non-Invasive Assessment of Hepatic Mitochondrial Metabolism by Positional Isotopomer NMR Tracer Analysis (PINTA). Nat. Commun. 8, 798

Glastonbury, C.A. et al. (2019) Cell-Type Heterogeneity in Adipose Tissue Is Associated with Complex Traits and Reveals Disease-Relevant Cell-Specific eQTLs. Am. J. Hum. Genet. 104, 1013-1024

Roci, I. et al. (2017) A Method for Measuring Metabolism in Sorted Subpopulations of Complex Cell Communities Using Stable Isotope Tracing. J. Vis. Exp. DOI: 10.3791/55011

Roci, I. et al. (2016) Metabolite Profiling and Stable Isotope Tracing in Sorted Subpopulations of Mammalian Cells. Anal. Chem. 88, 2707-2713

Llufrio, E.M. et al. (2018) Sorting Cells Alters their Redox State and Cellular Metabolome. Redox Biol. 16, 381-387

Binek, A. et al. (2019) Flow Cytometry Has a Significant Impact on the Cellular Metabolome. J. Proteome Res. 18, 169-181

Zecchin, A. et al. (2015) Metabolic Pathway Compartmentalization: An Underappreciated Opportunity? Curr. Opin. Biotechnol. 34, 73-81

Wellen, K.E. and Snyder, N.W. (2019) Should we consider subcellular compartmentalization of metabolites, and if so, how do we measure them? Curr. Opin. Clin. Nutr. Metab. Care 22, 347-354

Lewis, C.A. et al. (2014) Tracing Compartmentalized NADPH Metabolism in the Cytosol and Mitochondria of Mammalian Cells. Mol. Cell 55, 253-263

Ducker, G.S. et al. (2016) Reversal of Cytosolic One-Carbon Flux Compensates for Loss of the Mitochondrial Folate Pathway. Cell Metab. 23, 1140-1153 Lee, W.D. et al. (2019) Spatial-Fluxomics Provides a Subcellular-Co
Glutamine Metabolism in Cancer Cells. Nat. Commun. 10, 1351 Abu-Remaileh, M. et al. (2017) Lysosomal Metabolomics Reveals V-ATPase- and mTOR-Dependent Regulation of Amino Acid Efflux from Lysosomes. Science. 358, 807-813

Bayraktar, E.C. et al. (2019) MITO-Tag Mice Enable Rapid Isolation and Multimodal Profiling of Mitochondria from Specific Cell Types in vivo. Proc. Natl. Acad. Sci. 116, 303-312

Hu, Y. et al. (2018) Single Cell Multi-Omics Technology: Methodology and Application. Front. Cell Dev. Biol. 6, 28

Liu, Y. et al. (2019) Advancing Single-Cell Proteomics and Metabolomics with Microfluidic Technologies. Analyst 144, 846-858

Zhang, L. and Vertes, A. (2015) Energy Charge, Redox State, and Metabolite Turnover in Single Human Hepatocytes Revealed by Capillary Microsampling Mass Spectrometry. Anal. Chem. 87, 10397-10405

Standke, S.J. et al. (2019) Mass Spectrometry Measurement of Single Suspended Cells Using a Combined Cell Manipulation System and a Single-Probe Device. Anal. Chem. 91, 1738-1742

Sun, C. et al. (2019) Spatially Resolved Metabolomics to Discover Tumor-Associated Metabolic Alterations. Proc. Natl. Acad. Sci. 116, 52-57 Ionization Mass Spectrometry Imaging. In Metabolomics: From Fundamentals to Clinical Applications 965 (Sussulini, A., ed), pp. 291-321, Springer 

MS/MS Data Acquisition without Sacrificing Spatial Resolution. J. Am. Soc. Mass Spectrom. 28, 1910-1918 Hansen, R.L. and Lee, Y.J. (2018) High-Spatial Resolution Mass Spectrometry Imaging: Toward Single Cell Metabolomics in Plant Tissues. Chem. Rec. 18, 65-77 Krasny, L. et al. (2015) Spatial Segmentation of MALDI FT-ICR MSI Data: A Powerful Tool to Explore the Head and Neck Tumor In Situ Lipidome. J. Am. Soc. Mass Spectrom. 26, 36-43 Zhang, L. and Vertes, A. (2018) Single-Cell Mass Spectrometry Approaches to Explore Cellular Heterogeneity. Angew. Chemie Int. Ed. 57, 4466-4477 Suppressed Glucose Oxidation In Vivo. Cell Metab. 28, 793-800

Tardito, S. et al. (2015) Glutamine Synthetase Activity Fuels Nucleotide Biosynthesis and Supports Growth of Glutamine-Restricted Glioblastoma. Nat. Cell Biol. 17, 1556-68

Liu, X. et al. (2018) Acetate Production from Glucose and Coupling to Mitochondrial Metabolism in Mammals. Cell 175, 502-513

Elia, I. et al. (2017) Proline Metabolism Supports Metastasis Formation and Could be Inhibited to Selectively Target Metastasizing Cancer Cells. Nat. Commun. 8, 15267

Kim, C.-W. et al. (2017) Acetyl CoA Carboxylase Inhibition Reduces Hepatic Steatosis but Elevates Plasma Triglycerides in Mice and Humans: A Bedside to Bench Investigation. Cell Metab. 26, 394-406

Yam, M. et al. (2019) Proline Mediates Metabolic Communication between Retinal Pigment Epithelial Cells and the Retina. J. Biol. Chem. 294, 10278-10289

$$
\text { Negative Breast Cancer. Nat. Med. 22, 427-432 }
$$

Vatner, D.F. et al. (2015) Insulin-Independent Regulation of Hepatic Triglyceride Synthesis by Fatty Acids. Proc. Natl. Acad. Sci. 112, 1143-1148

Kucejova, B. et al. (2016) Hepatic mTORC1 Opposes Impaired Insulin Action to Control Mitochondrial Metabolism in Obesity. Cell Rep. 16, 508-519

Cappel, D.A. et al. (2019) Pyruvate-Carboxylase-Mediated Anaplerosis Promotes Antioxidant Capacity by Sustaining TCA Cycle and Redox Metabolism in Liver. Cell Metab. 29, 1291-1305

Rauckhorst, A.J. et al. (2017) The Mitochondrial Pyruvate Carrier Mediates High Fat Diet-Induced Increases in Hepatic TCA Cycle Capacity. Mol. Metab. 6, 1468-1479

Sato, S. et al. (2018) Human Metabolomics Reveal Daily Variations under Nutritional Challenges Specific to Serum and Skeletal Muscle. Mol. Metab. 16, 1-11

Dyar, K.A. et al. (2018) Atlas of Circadian Metabolism Reveals System-wide Coordination and Communication between Clocks. Cell 174, 1571-1585

Estrella, M.A. et al. (2019) The Metabolites NADP+ and NADPH are the Targets of the Circadian Protein Nocturnin (Curled). Nat. Commun. 10, 2367

Eckel-Mahan, K.L. et al. (2013) Reprogramming of the Circadian Clock by Nutritional Challenge. Cell 155, 1464-1478 Biol. 20, 227-241

Kinouchi, K. et al. (2018) Fasting Imparts a Switch to Alternative Daily Pathways in Liver and Muscle. Cell Rep. 25, 3299-3314

Daurio, N.A. et al. (2019) Spatial and Temporal Studies of Metabolic Activity: Contrasting Biochemical Kinetics in Tissues and Pathways during Fasted and Fed States. Am. J. Physiol. Metab. 316, E1105-E1117 in Rodents. Nat. Methods 11, 629-632 
Toth, L.A. (2015) The Influence of the Cage Environment on Rodent Physiology and Behavior: Implications for Reproducibility of Pre-Clinical Rodent Research. Exp. Neurol. 270, 72-77 Pierozan, P. et al. (2017) The Choice of Euthanasia Method Affects Metabolic Serum Biomarkers. Basic Clin. Pharmacol. Toxicol. 121, 113-118

97 Makaryus, R. et al. (2011) The Metabolomic Profile during Isoflurane Anesthesia Differs from Propofol Anesthesia in the Live Rodent Brain. J. Cereb. Blood Flow Metab. 31, 1432-1442 Guo, N.-L. et al. (2017) Isoflurane Promotes Glucose Metabolism through Up-Regulation of miR-21 and Suppresses Mitochondrial Oxidative Phosphorylation in Ovarian Cancer Cells. Biosci. Rep. 37, BSR20170818 Lu, W. et al. (2017) Metabolite Measurement: Pitfalls to Avoid and Practices to Follow. Annu. Rev. Biochem. 86, 277-304

100 Riekeberg, E. and Powers, R. (2017) New Frontiers in Metabolomics: From Measurement to Insight. F1000Res. 6, 1148

101 Amberg, A. et al. (2017) NMR and MS Methods for Metabolomics. In Drug Safety Evaluation (Gautier, J.C., ed), pp. 229-258, Humana Press

102 Bingol, K. (2018) Recent Advances in Targeted and Untargeted Metabolomics by NMR and MS/NMR Methods. High-Throughput 7, 9

103 Midani, F.S. et al. (2017) The Importance of Accurately Correcting for the Natural Abundance of Stable Isotopes. Anal. Biochem. 520, 27-43

104 Millard, P. et al. (2012) IsoCor: Correcting MS Data in Isotope Labeling Experiments. Bioinformatics 28, 1294-1296

105 Altea-Manzano, P. et al. (2020) Analyzing the Metabolism of Metastases in Mice. In Metabolic Flux Analysis in Eukaryotic Cells 2088 (Nagrath, D., ed), pp. 93-118, Humana Press 